\title{
Methane Production from $\mathrm{H}_{2}+\mathrm{CO}_{2}$ Reaction: An Open Molecular Science Case for Computational and Experimental Studies
}

\author{
Stefano Falcinelli ${ }^{1, *}$, Andrea Capriccioli ${ }^{2}$, Marzio Rosi ${ }^{1,3}{ }^{\oplus}$, Carles Martì ${ }^{4}$, Marco Parriani ${ }^{1}$ and Antonio Laganà ${ }^{3}$ \\ 1 Department of Civil and Environmental Engineering, University of Perugia, Via G. Duranti 93, \\ 06125 Perugia, Italy; marzio.rosi@unipg.it (M.R.); marcoparriani@gmail.com (M.P.) \\ 2 EOS Energetics S.r.l.s., Via F. Buonamici 77, 00173 Roma, Italy; andrea.capriccioli1955@gmail.com \\ 3 SCITEC, CNR, Via Elce di Sotto 8, 06123 Perugia, Italy; lagana05@gmail.com \\ 4 Laboratoire de Chimie ENS de Lyon 46, allée d'Italie, CEDEX 07, 69364 Lyon, France; \\ carles.marti2@gmail.com \\ * Correspondence: stefano.falcinelli@unipg.it; Tel.: +39-075-585-3835
}

\section{check for} updates

Citation: Falcinelli, S.; Capriccioli, A.; Rosi, M.; Martì, C.; Parriani, M.; Laganà, A. Methane Production from $\mathrm{H}_{2}+\mathrm{CO}_{2}$ Reaction: An Open

Molecular Science Case for Computational and Experimental Studies. Physchem 2021, 1, 82-94. https://doi.org/10.3390/physchem 1010006

Academic Editors: Jacinto Sá and Sergei Manzhos

Received: 17 March 2021

Accepted: 31 May 2021

Published: 2 June 2021

Publisher's Note: MDPI stays neutral with regard to jurisdictional claims in published maps and institutional affiliations.

Copyright: (c) 2021 by the authors. Licensee MDPI, Basel, Switzerland. This article is an open access article distributed under the terms and conditions of the Creative Commons Attribution (CC BY) license (https:// creativecommons.org/licenses/by/ $4.0 /)$.

\begin{abstract}
The article illustrates the synergy between theoretical/computational advances and advanced experimental achievements to pursue green chemistry and circular economy technological implementations. The specific green chemistry focus concerns the production of carbon neutral fuels by converting waste carbon dioxide into methane. Both theoretical-computational and technological means were adopted to design a functional option implementing a heterogeneous catalysis process (Paul Sabatier (PS) catalytic reduction) to convert carbon dioxide into methane, and to further drive its evolution towards the employment of an alternative homogeneous gas phase plasma assisted technology. The details of both the theoretical and the experimental components of the study are presented and discussed. Future potential developments, including industrial ones, are outlined that are also from innovative collaborative economic prosumer model perspectives.
\end{abstract}

Keywords: carbon dioxide; carbon neutral fuels; global warming; methane production; waste reutilization

\section{Introduction}

In recent years it has largely been agreed that global warming is chiefly caused by the use of fossil fuels [1,2], with the emission of greenhouse gases (such as carbon dioxide, methane and nitrous oxide) being mainly responsible for the dramatic increase of environmental threats. Fuels that do not produce net greenhouse gas emissions (mainly $\mathrm{CO}_{2}$ ) are defined as carbon neutral fuels. This type of fuel can be produced by exploiting the electrolysis of water to generate hydrogen which is then used as a hydrogenating reagent for $\mathrm{CO}_{2}$ to produce methane via the well-known Sabatier reaction (see below). In this way, it is possible to transform a chemical species that is an environmental pollutant $\left(\mathrm{CO}_{2}\right)$ into an energy resource $\left(\mathrm{CH}_{4}\right)$ that can be used, for example, in the methane pipelines of public distribution networks. For this purpose and in order to be completely environmentally compatible, the so-called "power-to-gas" (P2G) technology is used, which uses electricity from renewable sources to produce gaseous fuels.

For this reason, a team of scientists and technologists came together with the skills necessary to design and build an apparatus converting waste carbon dioxide into (re-usable) methane. This effort gathered around the research laboratories of the University of Perugia (UPG, Perugia, Italy), including scientists from the University of the Basque Country in Vitoria (EHU, Vitoria, Spain), the University of Barcelona (UB, Barcelona, Spain), and the University of Toulouse (UT, Toulouse, France) as well as some technologists from Italian research institutions and companies working in the energy area ENEA, EOS Energetics (Roma), Master-up (Perugia), PLC System (Acerra), FASAR Elettronica-RadioAstroLab (Senigallia) and RDPower (Terni). The collaboration between these partners provided the 
skills for the theoretical-computational treatment of elementary molecular processes [3-5] and for the measuring of molecule-molecule (atom) and light-molecule (atom) collision cross section and rate coefficient [6-8], and the capacity of designing and assembling computer-controlled apparatuses. As a result, a novel apparatus using renewable energies to produce carbon neutral fuels through a chemical catalytic conversion of carbon dioxide is under development:

(1) A first operational line leading to the design of an apparatus implementing the following stages (as shown in Figure 1): (A) the electrolytic production of $\mathrm{H}_{2}$; (B) the Paul Sabatier (PS) catalytic reduction of $\mathrm{CO}_{2}$ to $\mathrm{CH}_{4} ;(\mathrm{C})$ the final storage and/or distribution of $\mathrm{CH}_{4}$ produced. All the elementary reactive and non-reactive molecular processes involved in these stages were designed and investigated through relevant theoretical, computational and experimental treatments [3].

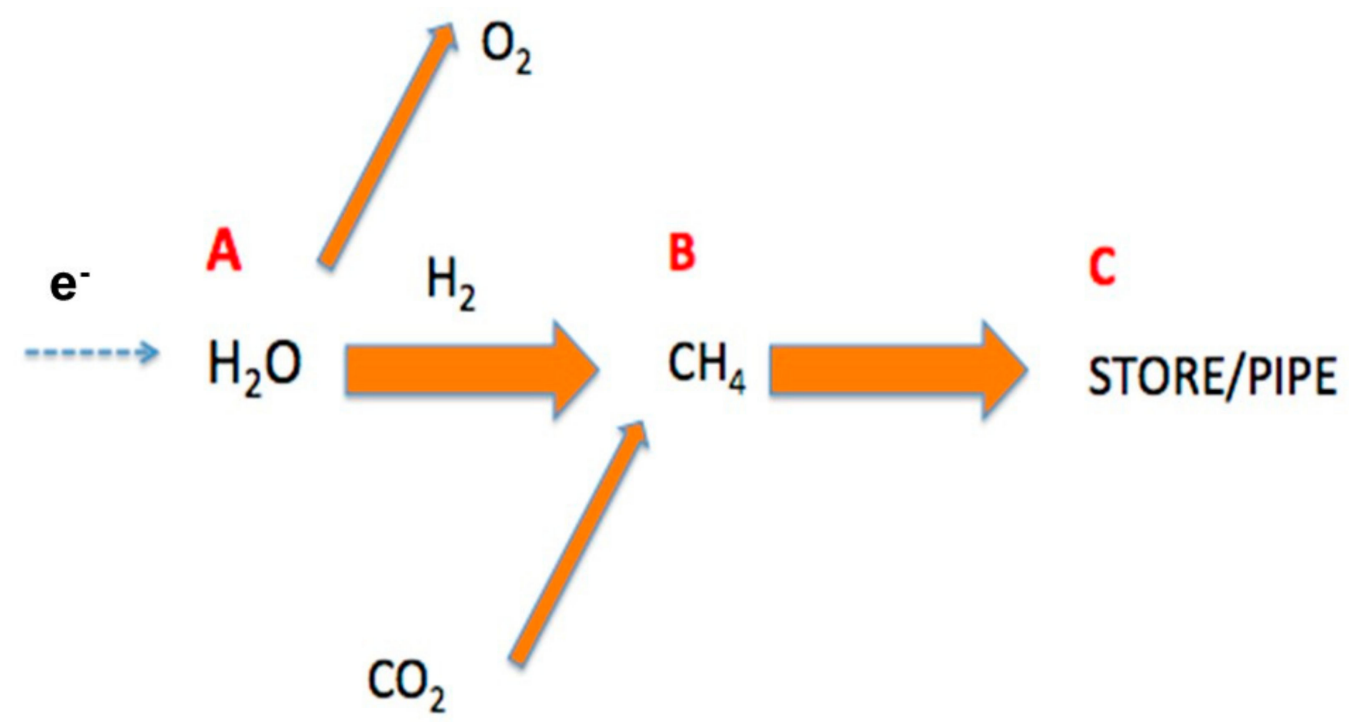

Figure 1. Starting from the electrolytic production of $\mathrm{H}_{2}$ (left side) which is the necessary reagent for the hydrogenation of carbon dioxide, sketch of the A, B and C steps of the process for the production/storage-distribution of methane.

(2) A second operational line leading to the design and implementation of the technological components of the low-cost hydrogen generation and methane production steps (with the related automation and numerical control (FASAR Elettronica)), with the former being realized at the Department of Enterprise Engineering, University of Rome "Tor Vergata", EOS Energetics. A prototype apparatus (named PROGEO) [3] was built thanks to additional financial and technical support by the PLC System company. Details of the apparatus and of the relevant computational investigations are provided in the next section.

(3) A third operational line to link PROGEO data handling and computations within the evolution stream of the European Open Molecular Science Cloud initiatives [5].

It has to be noted that a very interesting and promising alternative way to convert carbon dioxide into a useful chemical compound is the formation of methanol from $\mathrm{CO}_{2}$ through the reaction with hydrogen. The interested reader can find the state of the art of this topic in a recent review paper by Zhong et al. [9].

\section{Materials and Methods}

\subsection{The PROGEO Apparatus}

The PROGEO apparatus built at the PLC System site is a $30 \mathrm{~kW}$ (scalable to $1 \mathrm{MW}$ ) innovative prototype reactor $[3,10]$ and in its current configuration (see Figure 2) is operative in the laboratory of "Chemical Technologies" of the Dipartimento di Ingegneria Civile ed Ambientale, University of Perugia (Italy). It is based on a validated laboratory technology for the production of carbon neutral methane using electricity from the public 
net and hydrogen generated by a commercial electrolyzer (optimized to maximize the $\mathrm{H}_{2}$ production rather than its purity) to feed the catalytic conversion of a $\mathrm{CO}_{2}$ flux originating from any kind of sources (including off-line filled bottles). This involves indirect use of $\mathrm{H}_{2}$ as an energy vector (the direct and systematic use of $\mathrm{H}_{2}$ is more difficult because of its low viscosity and high diffusivity) that reduces the carbon dioxide on a nickel-based commercial catalyst. In the design and construction the skills of PROGEO have been used and the know-how of ENEA, EOS Energetics and UPG (Dipartimento di Ingegneria Civile ed Ambientale (DICA) and Dipartimento di Chimica, Biologia e Biotecnologie (DCBB)) on the theoretical-computational treatment of elementary molecular processes and the expertise on molecule-molecule (atom)and light-molecule (atom) collision cross section and rate coefficient measurements [4-8]. In addition, the project also utilized the electronic structure calculation competency of LCPQ [11]. Additionally, EHU conducted the fitting and modeling of potential energy surfaces together for dynamical calculations [12] and UB analyzed the integration of coupled kinetic equations related to the mechanism of the catalyzed reactions [13]. The technological competencies of ENEA, EOS Energetics, RDPower, PLC System [14], FASAR Elettronica and RadioAstroLab [15] were also extensively exploited.

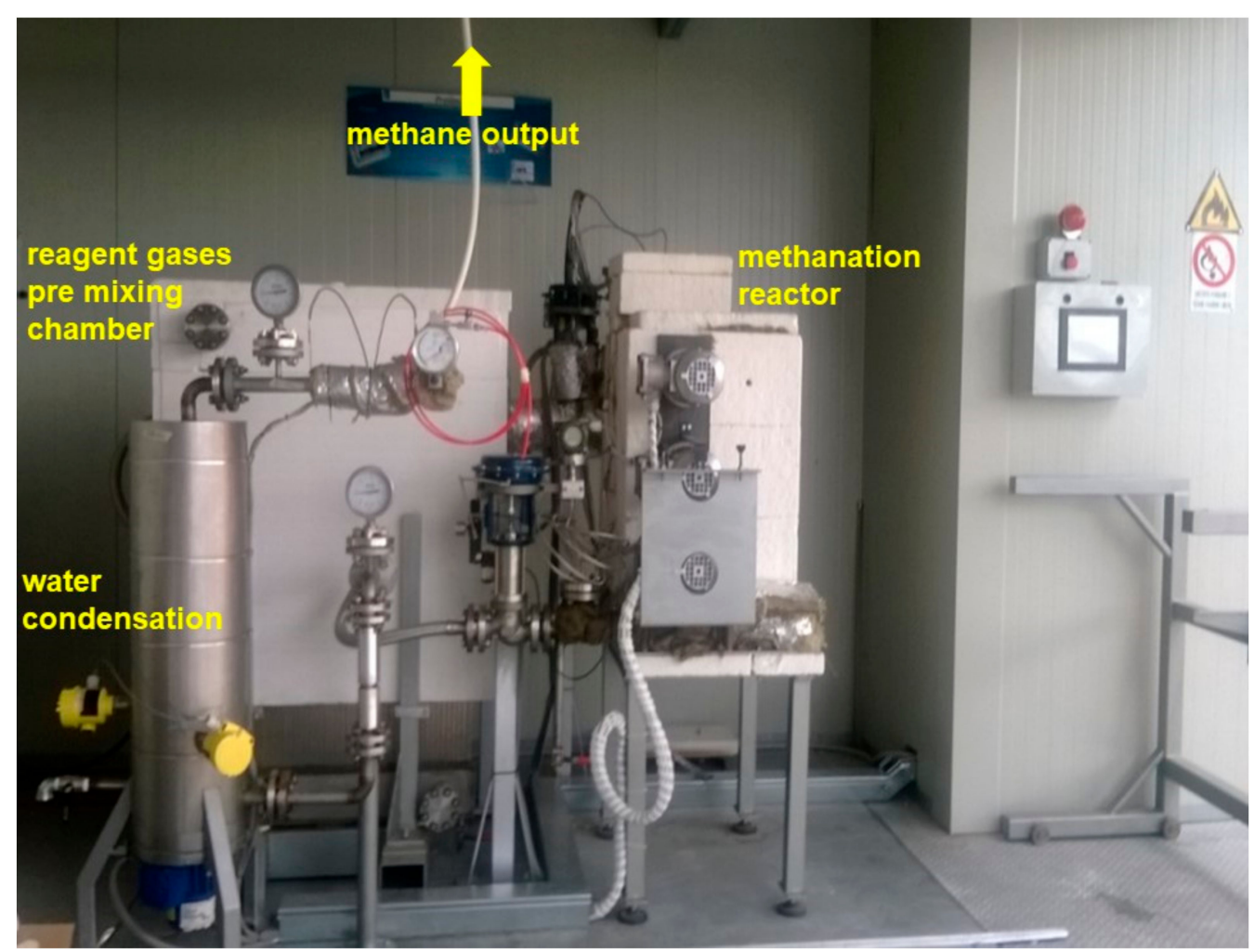

Figure 2. The PROGEO methanation reactor prototype apparatus operating in the DICA laboratory.

Designing and assembling the laboratory apparatuses has involved the following major components: (a) designing the composition of the different hardware components of the overall PROGEO apparatus; (b) selecting and integrating the commercial electrolyzer for the production of $\mathrm{H}_{2}$; (c) setting the characteristics of the Paul Sabatier reactor so as to maximize the recovery of the heat produced by the process (the process is exoergic with $\Delta \mathrm{G}_{298 \mathrm{~K}}=-130.8 \mathrm{~kJ} / \mathrm{mol}$ and this makes, in principle, the reaction self-sustainable with no need of external energy supply other than the activation one at the beginning of the reaction process, because the heat of reaction produced can be used to keep the chemical reactor at the operating temperature (about $\left.280^{\circ} \mathrm{C}\right)$ ); (d) adopting the solid state catalyzer (KATALCOJM 11-4MR, a Ni based metal alloy commercialized by Johnson Matthey [16]); (e) measuring typical yields of the PROGEO apparatus (see Section 3.1). 


\subsection{The Key Computational Outcomes}

One important goal of the PROGEO project was to compare accurate theoretical simulations to the experimental outcomes and provide a flexible test bed for enabling an improvement of the process. Heterogeneous catalysis employing solid catalysts for gas reactions involves a large list of several elementary surface processes in which different mechanisms can compete in both main and side reactions. Our simulations were based on a Kinetic Monte Carlo (KMC) (see Reference [17] and references therein) treatment of the kinetics of the surface catalyzed gas phase processes expected to be involved in the PROGEO apparatus by making use of a rejection-free algorithm.

The goal of the simulation was to reproduce the measured temperature dependence of the $\mathrm{CH}_{4}$ yield (see Figure 3 below) and single out the role played by the different elementary steps in the overall mechanism once a satisfactory agreement with the experiment was obtained. To this end, the set of differential equations relating to the consumption and the formation of the species that intervene in the included elementary processes and the concentration of the species of interest, depending on the relevant direct and inverse rate coefficients that are integrated. Particular care was therefore devoted to include an accurate description of the adsorption, desorption of reactants and reaction intermediates as well as surface diffusion and surface reactions [17]. When appropriate, in order to accelerate the calculations steady-state (assuming that the net rate of formation for intermediates is zero which does not imply that the coverage by the intermediates is small) and quasiequilibrium approximations (using the corresponding equilibrium equations instead of the kinetic equations for the fast steps) can also be introduced (see Reference [17] and references therein).

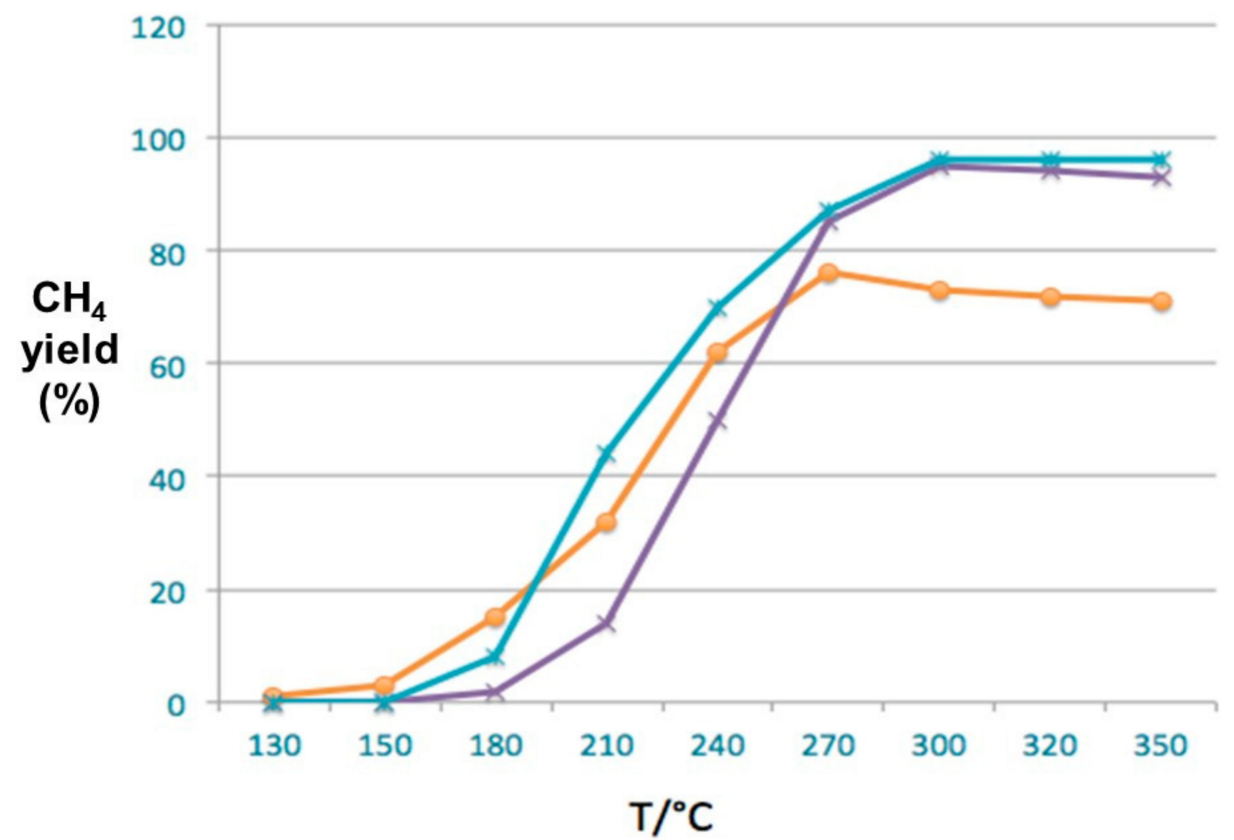

Figure 3. $\mathrm{CH}_{4}$ yield of the PROGEO apparatus at different values of the $\mathrm{CO}_{2} / \mathrm{H}_{2}$ ratio, plotted as a function of the temperature T. The following $\mathrm{CO}_{2} / \mathrm{H}_{2}$ ratios are considered: $1 / 3$ (hazelnut color), $1 / 4$ (violet), $1 / 5$ (blue).

In the KMC approach, the catalyst is represented as a symbolic grid of $25 \times 25$ double unit cells ensuring a good compromise between accuracy and computing time demand. On each grid point the value of the rate of the occurring different elementary processes is set to be proportional (through a rate coefficient $k$ ) to the concentration of the intervening species powered to the reaction partial order. In this way the concentration of the involved species (weighted by the adsorbed fraction) varies (i.e., the involved species are either formed or consumed) at the considered grid sites. Table 1 shows the elementary processes (left hand 
side column) involved in the proposed mechanism together with the related forward and backward (central and right-hand side columns) activation energy $\left(E_{a}\right)$ values taken from Reference [17].

Table 1. Elementary processes (left column) intervening in the overall catalytic $\mathrm{H}_{2}+\mathrm{CO}_{2}$ process and related activation energies $\left(E_{a}\right)$ for the forward (central column) and reverse (right column) processes taken from Reference [17]. Species followed by an asterisk $\left({ }^{*}\right)$ refer to adsorbed ones, while asterisks alone refer to free adsorption sites.

\begin{tabular}{|c|c|c|}
\hline Step & Ea Forward $(\mathrm{kJ} / \mathrm{mol})$ & Ea Reverse (kJ/mol) \\
\hline $\mathrm{CO}_{2}+{ }^{*} \leftrightarrow \mathrm{CO}_{2}^{*}$ & 0.0 & 8.3 \\
\hline $\mathrm{H}_{2}+2^{*} \leftrightarrow 2 \mathrm{H}^{*}$ & 4.0 & 77.1 \\
\hline $\mathrm{CO}+{ }^{*} \leftrightarrow \mathrm{CO}^{*}$ & 0.0 & 127.7 \\
\hline $\mathrm{H}_{2} \mathrm{O}+* \leftrightarrow \mathrm{H}_{2} \mathrm{O}^{*}$ & 0.0 & 49.0 \\
\hline $\mathrm{CO}_{2}^{*}+\mathrm{H}^{*} \leftrightarrow \mathrm{COOH}^{*}+{ }^{*}$ & 113.1 & 155.6 \\
\hline $\mathrm{CO}_{2}^{*}+2 \mathrm{H}^{*} \leftrightarrow \mathrm{C}(\mathrm{OH})_{2}^{*}+2^{*}$ & 292.3 & 217.8 \\
\hline $\mathrm{CO}_{2}^{*}+{ }^{*} \leftrightarrow \mathrm{CO}^{*}+\mathrm{O}^{*}$ & 93.7 & 169.3 \\
\hline $\mathrm{COOH}^{*}+{ }^{*} \leftrightarrow \mathrm{CO}^{*}+\mathrm{OH}^{*}$ & 306.8 & 308.7 \\
\hline $\begin{array}{l}\mathrm{C}(\mathrm{OH}) 2^{*}+\mathrm{H}^{*} \leftrightarrow \mathrm{CH} 2 \mathrm{O}^{*}+ \\
\mathrm{OH}^{*}\end{array}$ & 98.7 & 125.7 \\
\hline $\mathrm{CH}_{2} \mathrm{O}^{*}+\mathrm{H}^{*} \leftrightarrow \mathrm{CH}_{2}^{*}+\mathrm{OH}^{*}$ & 163.7 & 154.1 \\
\hline $\mathrm{CO}^{*}+{ }^{*} \leftrightarrow \mathrm{C}^{*}+\mathrm{O}^{*}$ & 237.4 & 111.8 \\
\hline $\mathrm{CO}^{*}+2 \mathrm{H}^{*} \leftrightarrow \mathrm{CH}^{*}+\mathrm{OH}^{*}+*$ & 221.4 & 146.1 \\
\hline $2 \mathrm{CO}^{*} \leftrightarrow \mathrm{CO}_{2}^{*}+\mathrm{C}^{*}$ & 339.6 & 109.0 \\
\hline $\mathrm{C}^{*}+\mathrm{H}^{*} \leftrightarrow \mathrm{CH}^{*}+*$ & 69.2 & 154.1 \\
\hline $\mathrm{CH}^{*}+\mathrm{H}^{*} \leftrightarrow \mathrm{CH}_{2}^{*}+{ }^{*}$ & 68.2 & 61.9 \\
\hline $\mathrm{CH}_{2}{ }^{*}+\mathrm{H}^{*} \leftrightarrow \mathrm{CH}_{3}^{*}+{ }^{*}$ & 71.4 & 105.6 \\
\hline $\mathrm{CH}_{3}^{*}+\mathrm{H}^{*} \leftrightarrow \mathrm{CH}_{4}+2^{*}$ & 137.4 & 178.7 \\
\hline $\mathrm{O}^{*}+\mathrm{H}^{*} \leftrightarrow \mathrm{OH}^{*}+^{*}$ & 137.9 & 116.0 \\
\hline $\mathrm{OH}^{*}+\mathrm{H}^{*} \leftrightarrow \mathrm{H}_{2} \mathrm{O}^{*}+*$ & 137.9 & 99.9 \\
\hline $\mathrm{H}^{*}+{ }^{*} \leftrightarrow^{*}+\mathrm{H}^{*}$ & 13.0 & 13.0 \\
\hline $\mathrm{CO}^{*}+{ }^{*} \leftrightarrow^{*}+\mathrm{CO}^{*}$ & 10.0 & 10.0 \\
\hline $\mathrm{O}^{*}+{ }^{*} \leftrightarrow^{*}+\mathrm{O}^{*}$ & 48.0 & 48.0 \\
\hline $\mathrm{OH}^{*}+{ }^{*} \leftrightarrow^{*}+\mathrm{OH}^{*}$ & 21.0 & 21.0 \\
\hline
\end{tabular}

Due to the large number of elementary processes involved in the PS reaction, a kinetic model was constructed by formulating their rate coefficients (for both the forward and the reverse ones) as $k=\left(k_{B} T / h\right) \exp \left(-E_{a} / k_{B} T\right)$ where $k_{B}$ is the Boltzmann constant, $T$ is the temperature, $h$ is the Plank constant and $E_{a}$ is the already mentioned activation energy (see Table 1) for species adsorbed on the $\mathrm{Ni}$ (111) surface (i.e., the most active surface for the given process). Using the activation energy values given in the table and the appropriate pre-exponential factor, the time evolution of the system components was computed at the desired conditions of temperature, pressure and initial gas phase molar fractions.

In order not to lose computational accuracy, some optimizations were adopted by the KMC simulations. This is the case, for example, of the diffusion rates which are far too large compared with the reactive ones. Because of this most of the computational effort is spent in simulating diffusion (that, due to the geometric features of the solid, is largely irrelevant to reach convergence on the actual value of the reactive properties). For this reason, to the end of exalting the role of the reactive processes, the pre-exponential factor of the diffusive processes was multiplied by a scaling factor $(\alpha)$ that largely increased the time step and enabled longer time simulations (repeated checks were performed to avoid changes in the final result). The finally adopted values of $\alpha$ were $10^{-4}, 10^{-5}, 10^{-2}, 10^{-3}$ for the processes $\mathrm{H}^{*}+{ }^{*} \rightarrow^{*}+\mathrm{H}^{*}, \mathrm{CO}^{*}+{ }^{*} \rightarrow^{*}+\mathrm{CO}^{*}, \mathrm{O}^{*}+{ }^{*} \rightarrow^{*}+\mathrm{O}^{*}, \mathrm{OH}^{*}+{ }^{*}{ }^{*}+\mathrm{OH}^{*}$, respectively.

An important contribution of such computational investigation to the understanding of the overall catalytic process was in singling out that the rate-determining step of the overall process is the hydrogenation of the $\mathrm{CO}$ adsorbed on the surface of the catalyst, which 
accounts for more than $90 \%$ of the produced methane. In order to better consolidate such a result by taking into account the fact that, as discussed in Reference [3], the concentrations of the gas species vary while the gas flows, our KMC treatment (called finite-volumereactor) splits the simulation time in intervals and at the end of each interval partial and total pressures are recalculated in order to estimate the number of reacted species and determine the actual concentrations for the next time interval. This iteration is repeated until satisfactory convergence is reached.

The role played by the $\mathrm{CO}$ adsorbed on the surface of the catalyst in producing methane (singled out by the just mentioned computational simulations) highlights the fact that the stretching of the $\mathrm{CO}$ bond is a preliminary condition for the production of $\mathrm{CH}_{4}$ and that any research effort spent in enhancing processes weakening the $\mathrm{CO}$ bond directly in the gas phase (see, e.g., Reference [3]) shall provide valid alternatives to heterogeneous catalysis. This is what prompted the investigation of the possibility of dissociating $\mathrm{CO}_{2}$ into either $\mathrm{CO} / \mathrm{O}$ or $\mathrm{CO}^{+} / \mathrm{O}^{+}$(neutral or ionic pairs in which the $\mathrm{CO}$ bond is stretched) directly in the gas phase and of making it react with hydrogen by means of a plasma generation in a $\mathrm{CO}_{2} / \mathrm{H}_{2}$ gas mixture.

\section{Results and Discussion}

\subsection{The Homogeneous Gas-Phase Plasma Assisted Catalysis}

This section presents very recent progress made in the DICA laboratory on the generation and characterization of different microwave discharge plasmas containing $\mathrm{CO}_{2} / \mathrm{H}_{2}$ mixtures. By such an experimental strategy, it is possible to convert carbon dioxide into various hydrocarbons such as methane, formic acid and/or dimethyl ether, as well as small amounts of $\mathrm{HCO}^{+}, \mathrm{H}_{2} \mathrm{CO}^{+}, \mathrm{H}_{3} \mathrm{CO}^{+}$, and $\mathrm{HCO}_{2}{ }^{+}$ions. In addition, $\mathrm{CO}^{+}$and $\mathrm{O}^{+}$ions are also generated in the plasmas with a high content of translational energy ranging between 2 and $6 \mathrm{eV}$. This enhances the chemical reactivity of the generated microwave discharge plasmas using gaseous $\mathrm{CO}_{2} / \mathrm{H}_{2}$ mixtures and allows us to consider the plasma-assisted technique as a pivotal strategy for the $\mathrm{CO}_{2}$ conversion into $\mathrm{CH}_{4}$ fuel in the field of chemical engineering master plans for new emerging catalysts development. The relevant experimental investigation is based on two main steps: (i) an experimental characterization of the main operative working conditions of the prototype methanation reactor PROGEO (see Figure 2); (ii) the production and relative chemical characterization of generated microwave plasmas containing $\mathrm{CO}_{2} / \mathrm{H}_{2}$ mixtures having different chemical compositions (1:3 and 1:5, respectively).

The analysis of the best working conditions for the PROGEO reactor allowed us to record the yields of carbon dioxide methanation when using a Ni-based solid catalyst as a function of the $\mathrm{CO}_{2} / \mathrm{H}_{2}$ molar ratio [3]. The obtained results are shown in Figure 3, recorded at the operating conditions of 2 bar and $300{ }^{\circ} \mathrm{C}$. As shown by Figure 3, there is a threshold at about $200{ }^{\circ} \mathrm{C}$ and the yield can rise quite steadily under proper conditions, up to almost $100 \%$. Optimizations of the methanation conditions can be obtained by: (a) introducing automated control procedures for temperature with the pre-warming the reactants reusing the heat released by the process and (b) regulating the carbon dioxide/hydrogen molar ratio with an excess of $\mathrm{H}_{2}$.

As already mentioned, a microwave discharge beam source specially built in the DICA laboratory and jointly working with a molecular beam apparatus operating at high vacuum conditions $\left(\sim 10^{-7}-10^{-8}\right.$ mbar) has been employed for the generation of $\mathrm{CO}_{2} / \mathrm{H}_{2}$ containing plasmas. Such an experimental apparatus, able to perform chemical characterization of generated plasmas by mass spectrometry [18,19] and fully described elsewhere [20-22], is shown in Figure $4 a$, while Figure 4 b shows a scheme of the microwave discharge device. The latter is essentially made by a cylindrical quartz pipe $(5 \mathrm{~cm}$ in length and $2 \mathrm{~cm}$ of diameter) inside a brass and water-cooled resonant cavity $(2450 \mathrm{MHz}$ and $70-200 \mathrm{~kW}$ typical operating power range) by a klystron and a devoted electronic control unit specially developed by FASAR Elettronica. 
(a)

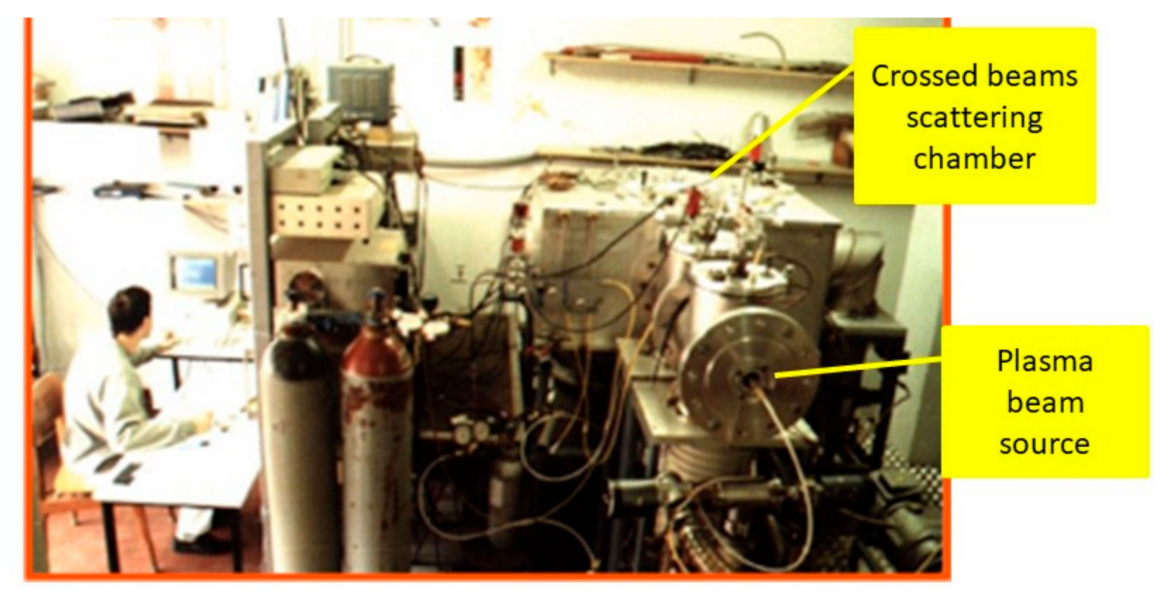

(b)

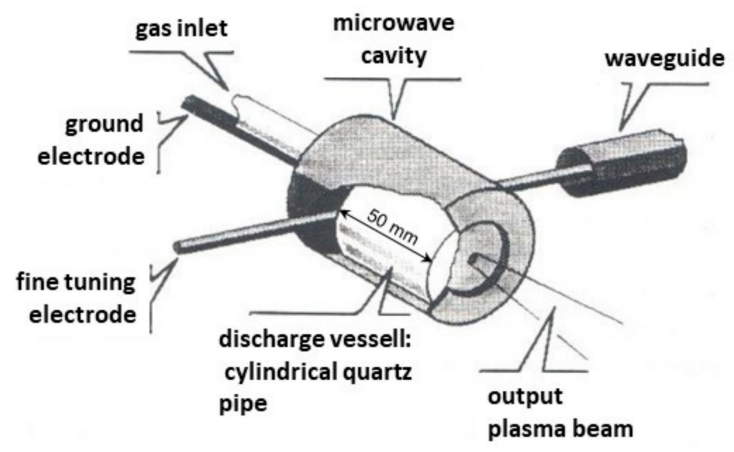

Figure 4. (a) The molecular beam apparatus used for $\mathrm{CO}_{2} / \mathrm{H}_{2}$ plasmas generation; (b) a scheme of the microwave discharge plasma source (see text).

To verify the possibility that the methanation reaction can take place via a plasma catalytic conversion by a plasma assisted version of the PROGEO apparatus, the generation of various $\mathrm{CO}_{2} / \mathrm{H}_{2}$ plasma mixtures using the microwave discharge device shown in Figure 4 has been explored. With a 1:1,1:3, and $1: 5 \mathrm{CO}_{2}: \mathrm{H}_{2}$ composition, the percentage of $\mathrm{CO}_{2}$ dissociation according to the following reactions has been determined:

$$
\begin{gathered}
\mathrm{CO}_{2}+\mathrm{e}^{-} \rightarrow \mathrm{CO}+\mathrm{O}+\mathrm{e}^{-}, \\
\mathrm{O}+\mathrm{O} \rightarrow \mathrm{O}_{2},
\end{gathered}
$$

Figure 5 a reports such data as a function of the applied power to the microwave discharge.

The data shown in Figure 5 were obtained by determining the $\mathrm{CO}_{2}$ dissociation percentage $\left(\% \mathrm{CO}_{2}\right.$ diss $)$ from the recording the $\mathrm{CO}_{2}{ }^{+}$ion intensity in the two experimental conditions of microwave discharge off $\left(\mathrm{I}_{\mathrm{off}}\right)$ and on $\left(\mathrm{I}_{\mathrm{on}}\right)$ via the following relation:

$$
\% \mathrm{CO}_{2} \text { diss }=100\left(\mathrm{I}_{\text {off }}-\mathrm{I}_{\mathrm{on}}\right) / \mathrm{I}_{\text {off }}
$$

The obtained data of Figure $5 \mathrm{a}$ are in very good agreement with previous measurements performed in various laboratories $[23,24]$. They clearly point out that the dissociation of $\mathrm{CO}_{2}$ is growing as the concentration of $\mathrm{H}_{2}$ increases: it is about $50 \%$ higher in the case of the $\mathrm{CO}_{2}: \mathrm{H}_{2}$ 1:5 mixture than the 1:1 one, reaching its maximum value of about $62 \%$ for a $200 \mathrm{~W}$ applied power. This data agrees with previous determinations by de la Fuente et al. [25]. These authors found higher $\mathrm{CO}_{2}$ decomposition values when the $\mathrm{CO}_{2}: \mathrm{H}_{2}$ concentration ratio decrease and reaches up to about $80 \%$ for a $\mathrm{CO}_{2}: \mathrm{H}_{2}$ ratio of $1: 3$, since $\mathrm{H}_{2}$ is able to act as a "catalyst" for such a process. The observation that a higher concentration of $\mathrm{H}_{2}$ favors the dissociation of $\mathrm{CO}_{2}$ in different $\mathrm{CO}_{2} / \mathrm{H}_{2}$ mixtures is an interesting case of reactions in which a reactant also acts as a catalyst in a complex mechanism. It should be noted that the recognition of such processes, despite being still in an immature state, is of great relevance in chemistry [26]. 

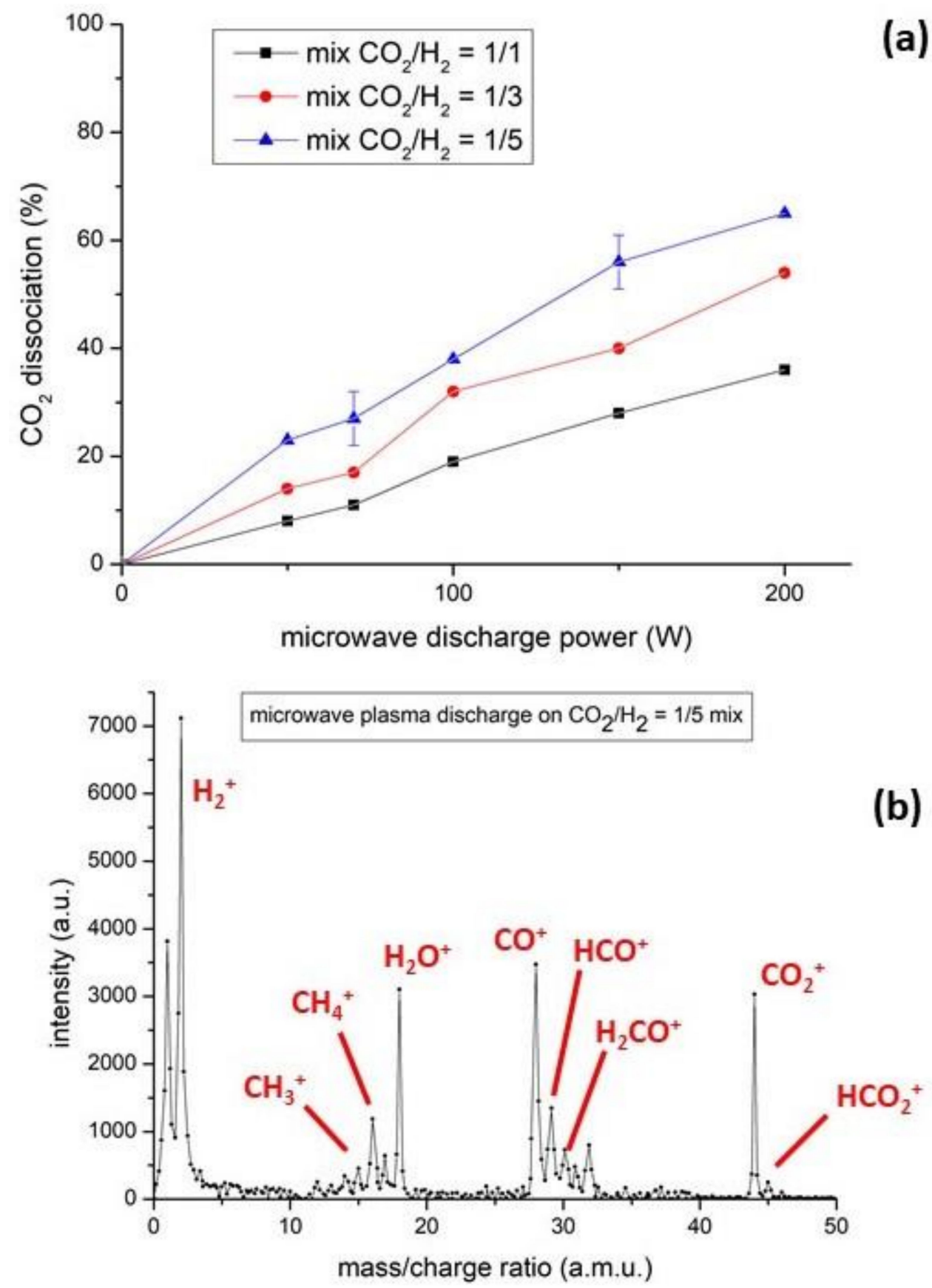

Figure 5. (a) The $\mathrm{CO}_{2} \%$ dissociation measured as a function of the applied microwave discharge power. The data are determined by keeping the inlet gas pressure at a constant value of $\sim 1800 \mathrm{~Pa}$ and for three different plasmas using 1:1, 1:3 and 1:5 $\mathrm{CO}_{2}: \mathrm{H}_{2}$ gas mixtures (see text). (b) The mass spectrum recorded for the microwave discharge plasma generated with a $1: 5 \mathrm{CO}_{2}: \mathrm{H}_{2}$ gas mixture composition (inlet gas pressure $\sim 1800 \mathrm{~Pa}$; applied microwave discharge power $\sim 180 \mathrm{~W}$ ).

Using the crossed beam apparatus shown in Figure 4 and the procedure described above, the analysis and characterization from a chemical point of view of the generated plasmas [27] have been done. Figure $5 b$ shows the recorded mass spectrum of the plasma, which has a 1:5 $\mathrm{CO}_{2}: \mathrm{H}_{2}$ composition. This spectrum clearly reveals the generation of: (i) various hydrocarbons: methane, formic acid and/or dimethyl ether; (ii) small amounts of $\mathrm{HCO}^{+}, \mathrm{H}_{2} \mathrm{CO}^{+}, \mathrm{H}_{3} \mathrm{CO}^{+}, \mathrm{HCO}_{2}{ }^{+}$ions; (iii) considerable amounts of the following ionic species: $\mathrm{H}^{+}, \mathrm{H}_{2}{ }^{+}, \mathrm{H}_{2} \mathrm{O}^{+}, \mathrm{CO}^{+}$and $\mathrm{CO}_{2}{ }^{+}$. The present results are in fairly good agreement with previous data from Hayashi et al. [28] who were able to produce methane, dimethyl 
ether and formic acid as well as several intermediate species such as $\mathrm{O}, \mathrm{OH}$, and $\mathrm{CO}$ in their surface discharge experiments. Furthermore, the data also confirm the observations by de la Fuente et al. [25] who detected $\mathrm{H}^{+}, \mathrm{H}_{2}{ }^{+}, \mathrm{H}_{2} \mathrm{O}^{+}, \mathrm{CO}^{+}$and $\mathrm{CO}_{2}{ }^{+}$ions and small amounts of methanol and ethylene in their microwave plasma reactor.

\subsection{Open Science, Circular Economy and Demo Applications}

\subsubsection{Open Science and Circular Economy}

Further advances of the PROGEO project in theoretical and computational research on chemical reactions are concerned with the exploitation of distributed and collaborative computing. To this end, a simulator of molecular processes that was able to accurately estimate detailed efficiency parameters of elementary chemical reactions was developed [29,30]. The simulator was then implemented on the grid and later on the cloud in order to gain efficiency in accuracy sensitive molecular science applications (e.g., astro-chemistry, combustion, environment, education, etc.) [31-37]. More recently, these activities were included within the European Open Science Cloud (EOSC) initiative [38-40] with the Molecular Open Science Enabled Cloud Services (MOSEX) [41-44] project concerned with theoretical, computational and experimental activities for the post PROGEO development of renewable energies storage pursuing not only research and technological advance but also circular economy implementations. PROGEO is, in fact, also an important step forward in circular economy due to its clear "regenerative" nature. The scheme sketched in Figure 1 (in which the conversion of extracted and captured $\mathrm{CO}_{2}$ into $\mathrm{CH}_{4}$ is illustrated) drives the physical system back to the state of a fuel to be used for producing energy and produce $\mathrm{CO}_{2}$. This scheme can be, therefore, defined as circular and regenerative because in it the "differences in resource input, waste emission and energy leakage are minimized by slowing, closing and narrowing material and energy loops". More rigorously, the circular economy steps of the model of PROGEO for re-using carbon dioxide to produce methane are intrinsically regenerative (according to the production paradigm based on a simplified version of the Nordhaus model in Reference [45] based on the innovation stream generated by the creation of patents and by the consequent monopoly profit) because they are aimed at reducing the negative impact of the linear economy by operating a systemic shift, building long-term resilience and generating economic opportunities providing environmental and societal benefits. PROGEO is, therefore, a clear example of the meaning and practice of creating a new economic and industrial logic based on long-term sustainability (provided that the expected profit guaranteed by the creation of related patents is balanced by a maximization of the social welfare by reducing dynamic deadweight losses).

This activity has stimulated a specific aggregation of molecular science theorists and computationists within MOSEX to validate data (for their own use and archives coordinating an EU wide distribution of specific repositories managed via cloud access (DataHub/FedDataPlatform) operating an open instance on top of the EGI cloud) provided by more general kinetic data bases [46-51]. It also provides in silico studies at the service of atomistic simulations aimed at developing more efficient catalysts. This task provides cloud validation of data (parsing, organizing, publishing, analyzing and storing information), the planning of new experiments and the design of new calculations.

\subsubsection{Demo Applications}

The first demo case study we considered for the transfer of the PROGEO technology into real business was a large Sicilian consortium of wineries. The consortium is located in the far west of Sicily and 2000 people who grow over 30 different cultivars over 6000 hectares of land. In this case a systematic analysis of the $\mathrm{CO}_{2}$ produced by fermentation is being planned together with the measurements of the actual yields of its conversion into methane. On the average, $1.9 \mathrm{~kg}$ of $\mathrm{CO}_{2}$ (about one cubic meter at normal conditions) per liter of wine is produced from Marsala grapes fermentation that is, in general, of such purity that it does not require any filtering. That $\mathrm{CO}_{2}$ can be used directly to feed PROGEO (after being stored in large containers) for being reduced using the hydrogen obtained 
by electrolyzing water using electricity generated from renewable sources (wind and sun plants) installed at the winery. The produced methane too can be stored in containers for use by farm tractors, minibuses and cars of employees.

Figure 6 is an illustration of a more general scheme for demo circular applications, discussed for possible implementation with some colleagues of the Agricultural Faculty [52] and Technological Park [53].
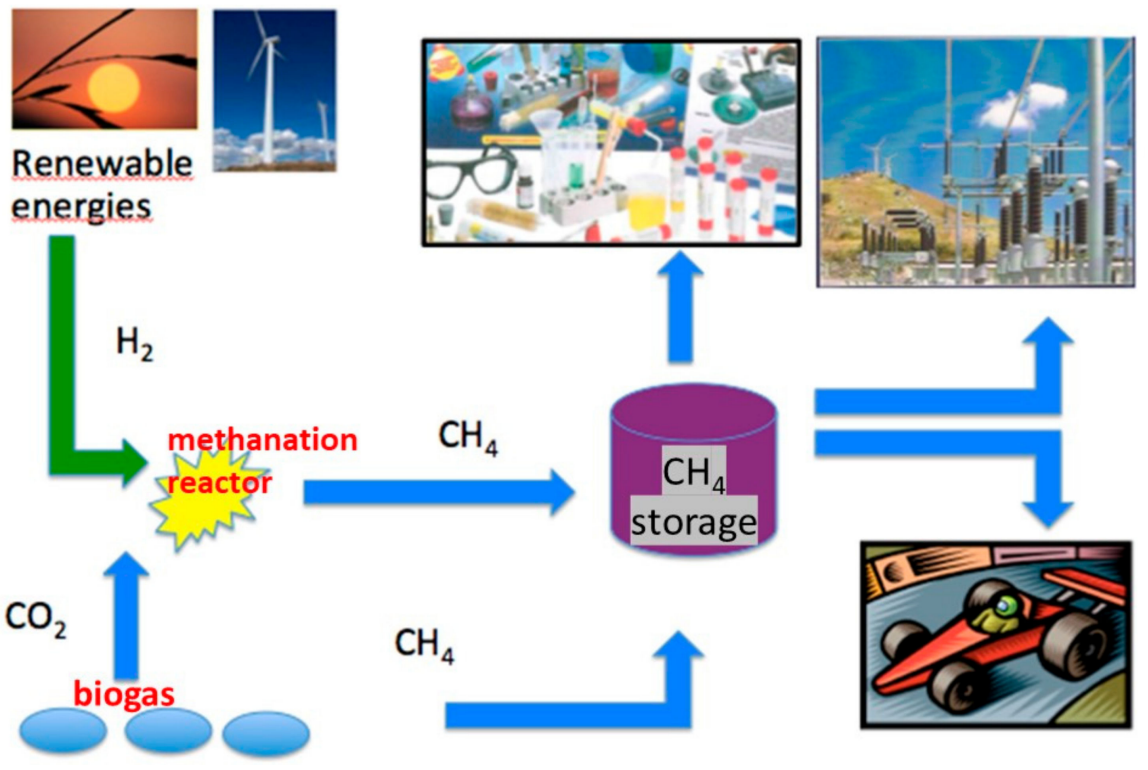

Figure 6. The circular economy prosumer scheme of PROGEO. In the lower-left corner of the figure the production of biogas is schematized: $\mathrm{CO}_{2}$ and $\mathrm{CH}_{4}$ main components, after a proper purification by specific membrane filtration technologies, are sent to the methanation reactor (vertical arrow), and to the gaseous fuel storage tank (horizontal arrow), respectively.

In the Figure, the scheme of an experimental plant for enriching biogas produced from agricultural feedstock by converting the fraction (about 50\%) of biogas generated by fermentation is illustrated. As mentioned in the previous demo application to wineries, PROGEO has a strong prosumer connotation, as is typical of MOSEX projects, together with a circular economy character. In this particular case and in that from fermentation of exhausted vegetable material supplied by the pharmaceutical drugs and herbal industry "VIS MEDICATRIX NATURAE S.r.l." (Marradi, Florence, Italy), methane is inserted into a circular economy scheme. The basic idea of this applied research is to use the $\mathrm{CO}_{2}$ fraction of the biogas produced (done in equal parts by methane and carbon dioxide) and to convert it into methane. This would allow the agricultural company to either reuse the produced $\mathrm{CH}_{4}$ as fuel for its internal purposes or to introduce it into the methane pipeline distribution network (according to the variation of needs) in a circular economy scheme with a "carbon neutral" strategy. Such a virtuous approach is in progress through a scientific collaboration aimed to analyze the quality of the produced biogas and to test it for the full methane conversion using the PROGEO prototype reactor.

In that case it was found that the company gets positive returns out of the innovation and will be also encouraged to increase the quantity of $\mathrm{CO}_{2}$ to convert because this increases the production efficiency. The process will continue, in fact, to produce at standard methods (still satisfying the market demand) while investing at the same time on R\&D to increase the productivity of the production factors and push for higher efficiency when moving to the next steps (the research and development variable cost can be kept unaltered thanks to its positive effect on a perspective of profit increase in even further subsequent steps). This confirms that the circular economy's reuse of energy guarantees, through the registering of patents and the consequent temporary monopolistic situations, the fulfilment of the conditions of positive ecological externality for the involved companies. 


\section{Conclusions}

PROGEO, a prototype reactor devoted to carbon dioxide methanation was developed to produce carbon neutral methane via chemical conversion of $\mathrm{CO}_{2}$ waste flue gases using renewable energy, in a circular economy strategy. It was characterized in its best operative conditions determining yields of methanation by the Sabatier reaction of about $84 \%$, where a Ni-based solid catalyst has been employed.

Furthermore, an experimental effort aimed to investigate a new reaction pathway without the use of the solid catalyst, has been undertaken and interesting and promising data collected exploring mechanisms via plasma generation using microwave discharges over $\mathrm{CO}_{2}+\mathrm{H}_{2}$ gas mixtures were highlighted. They demonstrate the generation in the exploited plasmas of simple hydrocarbons as methane, formic acid and/or dimethyl ether, small amount of $\mathrm{HCO}^{+}, \mathrm{H}_{2} \mathrm{CO}^{+}, \mathrm{H}_{3} \mathrm{CO}^{+}, \mathrm{HCO}_{2}{ }^{+}$ions, and considerable quantities of $\mathrm{CO}^{+}$ and $\mathrm{O}^{+}$ions, with high kinetic energy content, ranging between 2 and $6 \mathrm{eV}$. These ions formed by the Coulomb explosion of $\mathrm{CO}_{2}{ }^{2+}$ molecular dictations could be responsible for the enhanced chemical reactivity of the generated plasmas.

Further theoretical and experimental efforts will move in two directions: (i) to make the use of the PROGEO prototype suitable to be employed in the industrial chain in order to treat waste gases and convert them into valuable fuels in a circular economy logic: to do this it will be necessary to develop a new type of low-cost hydrogen gas generator through a project that EOS Energetics is working on; (ii) to develop a hybrid plasma-catalytic solid system or a homogeneous gas-phase reaction where $\mathrm{CO}_{2} / \mathrm{H}_{2}$ reagent mixtures activated by a plasma generation could realize the methanation reaction by new microscopic mechanisms more favorable from both a kinetic and energetic point of view.

In conclusion, the authors expect that new theoretical/computational methods based on distributed computing and open science cloud technologies converge into a full exploitation of produced data fostering the establishing of a large number of prosumer activities. At the same time the innovative experimental efforts on the characterization of microscopic dynamics of elementary reactions [54-60] is expected to provide reliable data that will be useful for a better understanding of innovative carbon neutral technologies. Indeed, in the authors' laboratory it has been recently possible to fully describe for the first time the microscopic dynamics of state-to state chemi-ionization reactions as prototype oxidation processes occurring as primary steps in flames and plasmas. This new theoretical model is a semiclassical treatment which allows to predict quantum state resolved reaction cross sections, rate constants, geometry and energetics of the transition state for such important elementary reactions (for more details see References [54,60]).

Industry and regional authorities could include them into future energy strategies, systems for innovation and environmentally-sustainable development, as well as for new catalysts able to maximize the products yield in plasma assisted reactions.

Author Contributions: Conceptualization, S.F. and A.L.; methodology, validation and formal analysis, S.F., A.C., M.R. and A.L.; experimental investigation, S.F., A.C. and M.P.; theoretical and computational calculations and analysis, M.R., C.M. and A.L.; writing-original draft preparation, S.F. and A.L.; writing-review and editing, S.F., A.C., M.R., C.M. and A.L. All authors have read and agreed to the published version of the manuscript.

Funding: This research was funded by UNIVERSITÀ DEGLI STUDI DI PERUGIA (Italy), “Fondo Ricerca di Base, 2018, dell'Università degli Studi di Perugia" (Project Titled: Indagini teoriche e sperimentali sulla reattività di sistemi di interesse astrochimico), ITALIAN MIUR and UNIVERSITÀ DEGLI STUDI DI PERUGIA(Italy), Program “Dipartimenti di Eccellenza 2018-2022”.

Institutional Review Board Statement: Not applicable.

Informed Consent Statement: Not applicable.

Conflicts of Interest: The authors declare no conflict of interest. 


\section{References}

1. Cook, J.; Nuccitelli, D.; Green, S.A.; Richardson, M.; Winkler, B.; Painting, R.; Way, R.; Jacobs, P.; Skuce, A. Quantifying the consensus on anthropogenic global warming in the scientific literature. Environ. Res. Lett. 2013, 8, 2. [CrossRef]

2. Oreskes, N. Beyond the Ivory Tower: The Scientific Consensus on Climate Change. Science 2004, 306, 1686. [CrossRef] [PubMed]

3. Falcinelli, S.; Capriccioli, A.; Pirani, F.; Vecchiocattivi, F.; Stranges, S.; Martì, C.; Nicoziani, A.; Topini, E.; Laganà, A. Methane production by $\mathrm{CO}_{2}$ hydrogenation reaction with and without solid phase catalysis. Fuel 2017, 209, 802-811. [CrossRef]

4. Laganà, A.; Riganelli, A. Reaction and Molecular Dynamics; Springer: Berlin/Heidelberg, Germany, 1999; ISBN 3-540-41202-6.

5. Laganà, A.; Parker, G.A. Chemical Reactions Basic Theory and Computing; Springer International Publishing: New York, NY, USA, 2018; ISBN 978-3-319-62355-9.

6. Falcinelli, S.; Pirani, F.; Vecchiocattivi, F. The Possible role of Penning Ionization Processes in Planetary Atmospheres. Atmosphere 2015, 6, 299-317. [CrossRef]

7. Falcinelli, S.; Bartocci, A.; Cavalli, S.; Pirani, F.; Vecchiocattivi, F. Stereo-dynamics in collisional autoionization of water, ammonia, and hydrogen sulfide with metastable rare gas atoms: Competition between intermolecular halogen and hydrogen bonds. Chem. Eur. J. 2016, 22, 764-771. [CrossRef]

8. Falcinelli, S.; Rosi, M.; Cavalli, S.; Pirani, F.; Vecchiocattivi, F. Stereoselectivity in Autoionization Reactions of Hydrogenated Molecules by Metastable Noble Gas Atoms: The Role of Electronic Couplings. Chem. Eur. J. 2016, 22, 12518-12526. [CrossRef]

9. Zhong, J.; Yang, X.; Wu, Z.; Liang, B.; Huang, Y.; Zhang, T. State of the art and perspectives in heterogeneous catalysis of $\mathrm{CO}_{2}$ hydrogenation to methanol. Chem. Soc. Rev. 2020, 49, 1385-1413. [CrossRef]

10. PROGEO by PLC System. Available online: https:/ / www.plc-spa.com/en/plc-system-progeo.php (accessed on 11 March 2021).

11. Laboratoire de Chimie et Physique Quantiques-UMR5626. Available online: http://www.lcpq.ups-tlse.fr/?lang=fr (accessed on 11 March 2021).

12. Rampino, S.; Skouteris, D.; Laganà, A.; Garcia, E.; Saracibar, A. A comparison of the quantum state-specific efficiency of $\mathrm{N}+\mathrm{N}_{2}$ reaction computed on different potential energy surfaces. Phys. Chem. Chem. Phys. 2009, 11, 1752-1757. [CrossRef]

13. Prats, H.; Gamallo, P.; Illas, F.; Sayós, R. Comparing the catalytic activity of the water gas shift reaction on $\mathrm{Cu}(321)$ and $\mathrm{Cu}(111)$ surfaces: Step sites do not always enhance the overall reactivity. J. Catal. 2016, 342, 75-83. [CrossRef]

14. L'Energia Che Crea il tuo Futuro by PLC System. Available online: https://www.plc-spa.com/it/index.php (accessed on 11 March 2021).

15. RadioAstroLab. Available online: https://www.radioastrolab.it/ (accessed on 11 March 2021).

16. Chemical Processes by Johnson Matthey. Available online: http://www.jmprotech.com/methanation-catalysts-for-hydrogenproduction-katalco (accessed on 16 March 2021).

17. Martì Aliod, C. Networked Computing for Ab Initio Modelling the Chemical Storage of Alternative Energy, ITN-EJD-TCCM. Ph.D. Thesis, Università degli Studi di Perugia, Perugia, Italy, Universitè P. Sabatier de Toulouse, Toulouse, France, 14 December 2018.

18. Pei, L.; Carrascosa, E.; Yang, N.; Falcinelli, S.; Farrar, J.M. Velocity Map Imaging Study of Charge-Transfer and Proton-Transfer Reactions of $\mathrm{CH}_{3}$ Radicals with $\mathrm{H}_{3}{ }^{+}$. J. Phys. Chem. Lett. 2015, 6, 1684-1689. [CrossRef]

19. Brunetti, B.; Candori, P.; Cappelletti, D.; Falcinelli, S.; Pirani, F.; Stranges, D.; Vecchiocattivi, F. Penning Ionization Electron Spectroscopy of water molecules by metastable neon atoms. Chem. Phys. Lett. 2012, 539-540, 19-23. [CrossRef]

20. Falcinelli, S.; Vecchiocattivi, F.; Pirani, F. Adiabatic and nonadiabatic effects in the transition states of state to state autoionization processes. Phys. Rev. Lett. 2018, 121, 163403. [CrossRef]

21. Balucani, N.; Bartocci, A.; Brunetti, B.; Candori, P.; Falcinelli, S.; Pirani, F.; Palazzetti, F.; Vecchiocattivi, F. Collisional autoionization dynamics of $\mathrm{Ne}^{*}\left({ }^{3} \mathrm{P}_{2,0}\right)-\mathrm{H}_{2} \mathrm{O}$. Chem. Phys. Lett. 2012, 546, 34-39. [CrossRef]

22. Leonori, F.; Petrucci, R.; Balucani, N.; Casavecchia, P.; Rosi, M.; Berteloite, C.; Le Picard, S.D.; Canosa, A.; Sims, I.R. Observation of organosulfur products (thiovinoxy, thioketene and thioformyl) in crossed-beam experiments and low temperature rate coefficients for reaction $\mathrm{S}\left({ }^{1} \mathrm{D}\right)+\mathrm{C}_{2} \mathrm{H}_{4}$. Phys. Chem. Chem. Phys. 2009, 11, 4701-4706. [CrossRef]

23. Dobrea, S.; Mihaila, I.; Popa, G. Carbon dioxide dissociation in a 2.45 GHz microwave discharge. In Proceedings of the 1st ICPIG, Granada, Spain, 14-19 July 2013; p. 14.

24. Dobrea, S.; Mihaila, I.; Tiron, V.; Popa, G. Optical and mass spectrometry diagnosis of a $\mathrm{CO}_{2}$ microwave plasma discharge. Rom. Rep. Phys. 2014, 66, 1147-1154.

25. de la Fuente, J.F.; Moreno, S.H.; Stankiewicz, A.I.; Stefanidis, G.D. Reduction of $\mathrm{CO}_{2}$ with hydrogen in a non-equilibrium microwave plasma reactor. Int. J. Hydrog. Energy 2016, 41, 21067-21077. [CrossRef]

26. Tortora, C.; Mai, C.; Cascella, F.; Mauksch, M.; Seidel-Morgenstern, A.; Lorenz, H.; Tsogoeva, S.B. Speeding up Viedma Deracemization through Watercatalyzed and Reactant Self-catalyzed Racemization. ChemPhysChem 2020, 21, 1775-1787. [CrossRef]

27. Falcinelli, S. Fuel production from waste $\mathrm{CO}_{2}$ using renewable energies. Catal. Today 2020, 348, 95-101. [CrossRef]

28. Hayashi, N.; Yamakawa, T.; Baba, S. Effect of additive gases on synthesis of organic compounds from carbon dioxide using non-thermal plasma produced by atmospheric surface discharges. Vacuum 2006, 80, 1299-1304. [CrossRef]

29. Gervasi, O.; Lagana', A. SIMBEX: A portal for the a priori simulation of crossed beam experiments. Future Gener. Comput. Syst. 2004, 20, 703-716. [CrossRef]

30. Laganà, A.; Rampino, S.; Storchi, L.; Garcia, E.; Coletti, C.; Blurock, E.; Bo, C.; Mariotti, M.; Vitillaro, G. GEMS Expression of Interest for the EGI, EUDAT and INDIGO-Datacloud H2020 Project Proposal EINFRA12 (A). Virt\&l-Comm.10.2016.6. Available online: http:/ / services.chm.unipg.it/ojs/index.php/virtlcomm/article/view/151 (accessed on 16 March 2021). 
31. Laganà, A.; Riganelli, A.; Gervasi, O. On the structuring of the computational chemistry virtual organization COMPCHEM. Lect. Notes Comput. Sci. 2006, 3980, 665-674.

32. Towards a CMMST VRC Team Project Report. Available online: https://wiki.egi.eu/wiki/Towards_a_CMMST_VRC (accessed on 16 March 2021).

33. European Cost Action D23: Metalaboratories for Complex Computational Applications in Chemistry. Available online: https: / / www.cost.eu/actions/D23/\#tabs I Name:overview/ (accessed on 16 March 2021).

34. European Cost Action D37: Grid Computing in Chemistry. Available online: https:/ /www.cost.eu/actions/D37/\#tabs I Name: overview / (accessed on 16 March 2021).

35. European Chemistry Thematic Network. Available online: http:/ / ectn.eu/ (accessed on 16 March 2021).

36. Enabling Grids for E-sciencE III (EGEE III). Available online: https: / cordis.europa.eu/ project/ rcn/87264/ factsheet/ en (accessed on 16 March 2021).

37. EGI-Inspire. Available online: https://wiki.egi.eu/wiki/EGI-InSPIRE:Main_Page (accessed on 16 March 2021).

38. Laganà, A. Towards Open Molecular Science Cloud Services. Virt\&l-Comm.16.2019.5. Available online: http://services.chm unipg.it/ojs/index.php/virtlcomm/article/view/210 (accessed on 16 March 2021).

39. European Open Science Cloud. Available online: https:/ / ec.europa.eu/research/openscience/index.cfm?pg=open-science-cloud (accessed on 16 March 2021).

40. EOSCpilot. Available online: https: / / eoscpilot.eu/ (accessed on 16 March 2021).

41. Vitillaro, G.; Laganà, A. MOSEX: Molecular Open Science Enabled. Cloud Services. Virt\&l-Comm.20.2020.7. Available online: http:/ / services.chm.unipg.it/ojs/index.php/virtlcomm/article/view/248 (accessed on 2 April 2021).

42. Laganà, A.; Garcia, E. Astrochemistry: An Open Molecular Science Cloud Approach to Low Temperature Reactivity. Virt\&lComm.18.2019.3. Available online: http://services.chm.unipg.it/ojs/index.php/virtlcomm/article/view/219 (accessed on 16 March 2021).

43. Skouteris, D.; Balucani, N.; Faginas-Lago, N.; Falcinelli, S.; Rosi, M. Dimerization of methanimine and its charged species in the atmosphere of Titan and interstellar/cometary ice analogs. Astron. Astrophys. 2015, 584, A76. [CrossRef]

44. EChemTest by ECTN. Available online: http:/ / ectn.eu/committees/virtual-education-community/echemtest/ (accessed on 16 March 2021).

45. Laganà, A.; di Giorgio, L. A Circular Economy proposal on $\mathrm{CO}_{2}$ reuse to produce methane using energy from renewable sources. Lect. Notes Comput. Sci. 2018, 10962, 549-562.

46. QCArchive. Available online: https:/ / qcarchive.molssi.org/ (accessed on 16 March 2021).

47. NIST Chemical Kinetics Database. Available online: http:// kinetics.nist.gov (accessed on 16 March 2021).

48. Wakelam, V.; Herbst, E.; Loison, J.-C.; Smith, I.W.M.; Chandrasekaran, V.; Pavone, B.; Adams, N.G.; Bacchus-Montabonel, M.-C.; Bergeat, A.; Beroff, K.; et al. A kinetic Database for Astrochemistry (KIDA). AstroPhys. J. Suppl. Ser. 2012, 199, 21. [CrossRef]

49. McElroy, D.; Walsh, C.; Markwick, A.J.; Cordiner, M.A.; Smith, K.; Millar, T.J. The UMIST database for astrochemistry 2012. Astron. Astrophys. 2013, 550, A36. [CrossRef]

50. Laganà, A.; Gervasi, O.; Tasso, S.; Perri, D.; Franciosa, F. The ECTN Virtual Education Community prosumer model for promoting and assessing chemical knowledge. Lect. Notes Comput. Sci. 2018, 10964, 533-548.

51. Álvarez-Moreno, M.; de Graaf, C.; López, N.; Maseras, F.; Poblet, J.M.; Bo, C. Managing the computational chemistry big data problem: The ioChem-BD platform. J. Chem. Inf. Model. 2015, 55, 95-103. [CrossRef]

52. I.S.FORM. by CNR, Perugia. Available online: http:/ / www.iro.pg.cnr.it/ (accessed on 16 March 2021).

53. 3A Parco Tecnologico Agroalimentare Dell’Umbria, Pantalla Todi (Italy). Available online: http://www.parco3a.org (accessed on 16 March 2021).

54. Falcinelli, S.; Vecchiocattivi, F.; Pirani, F. General treatment for stereo-dynamics of state-to-state chemi-ionization reactions. Commun. Chem. 2020, 3, 64. [CrossRef]

55. Leonori, F.; Petrucci, R.; Balucani, N.; Hickson, K.M.; Hamberg, M.; Geppert, W.D.; Casavecchia, P.; Rosi, M. Crossed-Beam and Theoretical Studies of the $\mathrm{S}\left({ }^{1} \mathrm{D}\right)+\mathrm{C}_{2} \mathrm{H}_{2}$ Reaction. J. Phys. Chem. A 2009, 113, 4330-4339. [CrossRef]

56. De Petris, G.; Cartoni, A.; Rosi, M.; Barone, V.; Puzzarini, C.; Troiani, A. The Proton Affinity and Gas-Phase Basicity of Sulfur Dioxide. ChemPhysChem 2011, 12, 112-115. [CrossRef]

57. Alagia, M.; Balucani, N.; Candori, P.; Falcinelli, S.; Pirani, F.; Richter, R.; Rosi, M.; Stranges, S.; Vecchiocattivi, F. Production of ions at high energy and its role in extraterrestrial environments. Rend. Lincei Sci. Fis. Nat. 2013, 24, 53-65. [CrossRef]

58. Falcinelli, S.; Farrar, J.M.; Vecchiocattivi, F.; Pirani, F. Quantum-state controlled reaction channels in chemiionization processes: Radiative (optical—physical) and exchange (oxidative-chemical) mechanisms. Acc. Chem. Res. 2020, 53, 2248-2260. [CrossRef]

59. Podio, L.; Codella, C.; Lefloch, B.; Balucani, N.; Ceccarelli, C.; Bachiller, R.; Benedettini, M.; Cernicharo, J.; Faginas-Lago, N.; Fontani, F.; et al. Silicon-bearing molecules in the shock L1157-B1: First detection of SiS around a Sun-like protostar. Mon. Not. R. Astron. Soc. Lett. 2017, 470, L16-L20. [CrossRef]

60. Candori, P.; Falcinelli, S.; Pirani, F.; Tarantelli, F.; Vecchiocattivi, F. Interaction components in the hydrogen halide dication. Chem. Phys. Lett. 2007, 436, 322-326. [CrossRef] 